\title{
ВНЕШНЯЯ ТОРГОВЛЯ ВЕНЕСУЭЛЫ В ХХІ ВЕКЕ. ПРЕДЛОЖЕНИЯ И ВОЗМОЖНОСТИ ПО ДИВЕРСИФИКАЦИИ ЭКСПОРТА
}

\author{
(c) 2021 Клейди Янира Эспиноса \\ аспирант, Факультет международных экономических отношений \\ Финансовый университет при Правительстве Российской Федерации, Россия, Москва \\ E-mail: kleidyes@gmail.com
}

Внешняя торговля Венесуэлы на протяжении десятилетий характеризовалась моноэкспортом углеводородов. В этом смысле проводится описательный анализ, цель которого - понять феномен производственной и коммерческой структуры Венесуэлы, подчеркивая зависимость от экспорта нефти и его последствия для венесуэльской макроэкономики, поскольку он подвергает страну уязвимости перед внешними потрясениями, вызванными колебаниями цен на первичные ресурсы. Аналогичным образом, делаются некоторые предложения по диверсификации неэнергетического экспорта, а также с учётом значительных технологических изменений, которые переживает международная торговля услугами, основанными на знаниях, в рамках четвертой промышленной революции.

Ключевые слова: Внешняя торговля, нефть, экспорт, импорт, Венесуэла, США, санкции, BCV, PDVSA.

Согласно статистическим данным Центрального банка Венесуэлы (BCV 2018), внешняя торговля Венесуэлы за последние два десятилетия углубила свою моноэкспортную структуру в нефтяном секторе. Валютные поступления в Венесуэлу в результате экспорта с 1950 года на 95\% связаны с доходами от нефти, и, следовательно, экономика Венесуэлы зависит от цен и уровней добычи этого углеводорода. Характерно, что это поставило страну в положение крайней уязвимости, поскольку эти валютные поступления зависят от волатильности цен на сырую нефть на международном финансовом рынке.

Доказательством этого утверждения является эволюция макроэкономического поведения и нерегулярная тенденция экономических циклов в последние годы, в периоды нефтяного процветания, которые стимулировали экономический рост, основанный на внутреннем потреблении и импорте, но не влияющий на диверсификацию производственной деятельности, несмотря на предпринятые усилия, которые снизили долю нефтяного экспорта до минимума [1].

К 1925 году нефтяная промышленность уже была доминирующим фактором в экономике Венесуэлы. В 1928 году Венесуэла была вторым по величине производителем нефти в мире, а с 1930-х годов государственные доходы, прямо или косвенно получаемые от нефтяной деятельности, составляют более половины национального бюджета.
Когда высоко ценимый природный ресурс, такой как нефть, появляется в экономике на международном рынке, распределение государственных ресурсов и частные инвестиции будут отставать от ставок вознаграждения, предлагаемых рикардианской рентой, в ущерб другим секторам производства. Это приводит к нестабильности, поскольку вся экономика зависит от этого ведущего продукта, а экономика связана с неустойчивыми движениями на международном рынке. Этот ведущий продукт также вызывает, как и в Венесуэле, искажения реального обменного курса, поскольку из-за огромных инвестиций, которые он получает, реальный обменный курс переоценен, а остальные продукты теряют конкурентоспособность. Именно доходы от нефти стимулируют или замедляют спрос и инвестиции, то есть индустриализацию Венесуэлы.

Нефть была основным средством включения Венесуэлы в современные международные отношения. Этот фактор, в свою очередь, способствовал развитию политической культуры, которая, как считается, регулирует частную деятельность, способствует зависимости общества от государства и уязвимости к колебаниям цен на баррель нефти [2].

Отсутствие диверсификации экспорта привело к ухудшению экономической ситуации в стране из-за воздействия санкций и экономической и коммерческой блокады, введенных Coединенными Штатами и их союзниками на наци- 
ональную нефтяную промышленность (PDVSA), а также на макроэкономические и экономические показатели. Следует учитывать и коммерческие ошибки, совершенные внутри страны в течение указанного периода. Выход из договора Группы трех, денонсация Андского пакта, нерегулярный выход на Общий рынок стран Южного конуса (приостановка членства в 2017 году) [3] и отсутствие последовательной политики поощрения экспорта стали ответом на интеграционную стратегию, основанную на идеологических и политических критериях. Всё это не оказало никакого положительного влияния на внешнюю торговлю, не связанную с нефтью, вытеснив Венесуэлу из новых тенденций в международной торговле (рис. 1).

Как показано на графике, венесуэльский экспорт был представлен продажей нефти в течение десятилетий, и эта схема не изменилась. Поэтому отсутствие диверсификации было слабым местом для экономики Венесуэлы в последние 20 лет в связи со снижением добычи сырой нефти и, следовательно, из-за падения уровня ее экспорта, как следствие нехватки инвестиций. Следовательно, произошло снижение содержания традиционных месторождений. Агрессивная политика санкций, экономическая и торговая блокада, падение мировых цен на нефть нанесли удар по нефтяной промышленности Венесуэлы [4].

Экспортная система страны - это система, которая позволяет ей получать иностранную валюту для накопления капитала, осуществления инвестиций и импорта товаров и услуг. Экспорт нефти Венесуэлы неуклонно падал в течение нескольких лет, как и импорт.

Платежный баланс - это учетная запись всех денежных операций между страной и осталь- ным миром, обычно измеряемая кварталами или годами. Платежный баланс Венесуэлы в результате экономической депрессии в настоящее время отражает тревожные цифры.

Анализ финансовых отчетов PDVSA за 2014, 2015, 2016 и 2017 годы позволяет нам наблюдать за генерированием национального дохода указанной компанией, отражая следующее: за 2014 год компания получила доход в долларах на сумму 121895 млн. долл., 2015 год -72169 млн. долл., в 2016 году -48002 млн. долл., а в 2017 году - 31 млрд. долл.; Что касается прибыли, сообщенной PDVSA в 2014 году она составила 12465 млн. долл., в 2015 году - 2588 млн. долл. и в 2016 году - 1592 млн. долл.. Хотя с 2017 года данных не публиковалось, снижение основных доходов страны от экспорта нефти уже было заметно. Аналогичным образом, для 2017 года следует отметить, что экспорт нефти составил $98 \%$ от общего объема экспорта [5].

Экономические санкции 2019 года против PDVSA оказали значительное влияние, вызвав сокращение экспорта венесуэльской нефти, поскольку они изолировали страну от ее крупнейшего нефтяного рынка - Соединенных Штатов, на которые в 2018 году пришлось 35,6\% от общего объема экспорта. В период с 28 февраля по 1 апреля 2019 г. экспорт венесуэльской нефти в США впервые за всю историю международной торговли Венесуэлы упал на $100 \%$; Экспорт в Китай упал на $49,43 \%$ из-за отказа азиатской страны покупать венесуэльскую нефть вследствие угроз со стороны США, запрещающих вести торговлю в рамках нефтяной отрасли Венесуэлы. В результате Венесуэла была вынуждена переместить экспорт нефти в Индию, тем самым увеличив квоту для этой страны на $21,71 \%$, а для других стран на $1600 \%$. Эта ситуация критично

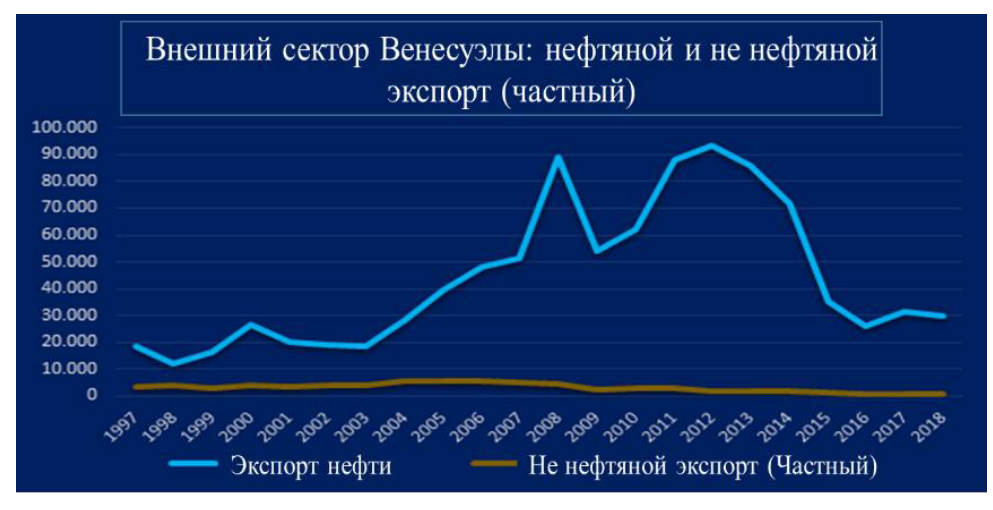

Рисунок 1.

Источник: Центральный банк Венесуэлы 


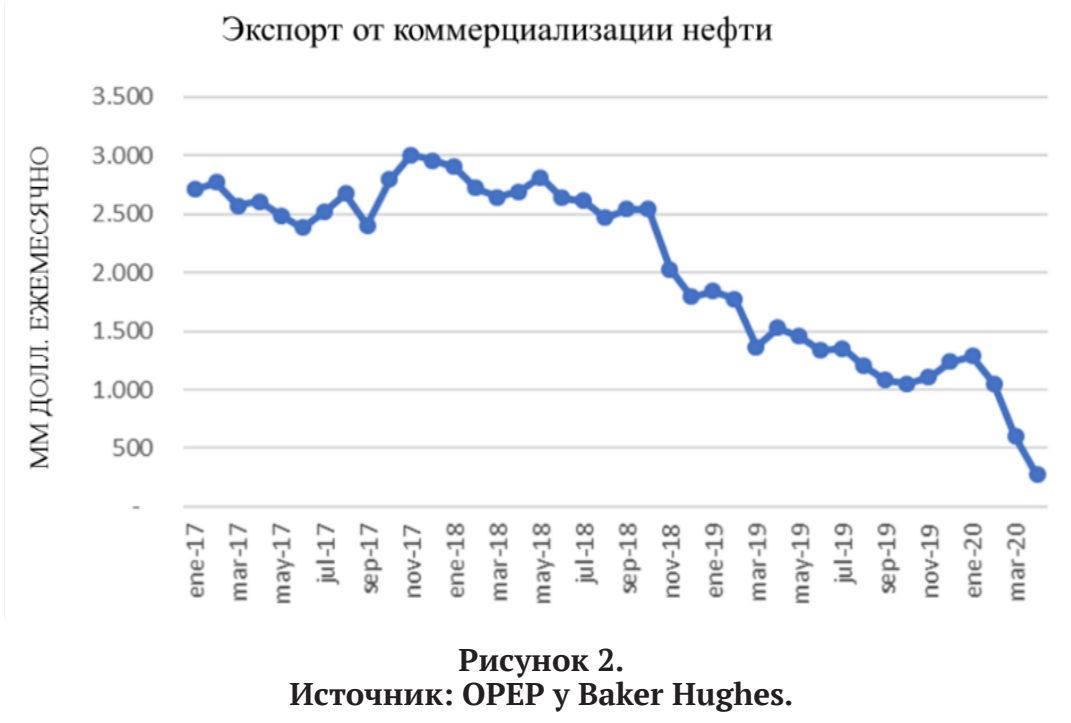

повлияла на добычу нефти, что на $36,4 \%$ было вызвано только санкциями в январе 2019 года против PDVSA [6].

Уровень ненефтяного экспорта всегда был очень низким, например, согласно данным, опубликованным Центральным банком Венесуэлы (BCV), за период с 2013 по 2018 год экспорт товаров и услуг составил 3,15 млрд. долл. (2013), 2944 млн. долл. (2014), 2100 млн. долл. (2015), 1461 млн. долл. (2016), 2533 млн. долл. (2017) и 3867 млн. долл. (2018). Эти цифры не важны для страны, которая десятилетиями экспортировала нефть [7].

Последствия падения экспорта нефти и ненефтяного экспорта отражены в сокращении экономической активности в годовом исчислении, которая, согласно данным, опубликованным Центральным банком Венесуэлы (BCV), в первом квартале 2019 года составила 26,8\% по сравнению с аналогичным периодом 2018 года. Контракты сокращаются шестой год подряд. По оценкам Экономической комиссии для Латинской Америки и Карибского бассейна (ЭКЛАК) эта динамика сохранится в оставшуюся часть года, а это означает, что ежегодное падение составит 28\%. Это сокращение активности проявилось как в нефтяном, так и в ненефтяном секторах. Во-первых, следует отметить резкое сокращение добычи сырой нефти в 2019 году. С другой стороны, все виды деятельности, не связанные с нефтью, также сократились: резкое падение, наблюдавшееся в обрабатывающей промышленности, строительстве, особенно в секторе финансовых услуг, которое по оценкам превышает 50\% [8].

Аналогичным образом, по оценкам ЭКЛАК, экспорт венесуэльских товаров и услуг упал на 34\% в 2019 году после падения на 1,0\% в 2018 году. Это сокращение экспорта в 2019 году отражает снижение средней цены венесуэльской нефтяной корзины сырой нефти, которая упала на 7,6\%, а также сокращение объемов экспорта, которое оценивается в 32\%. В 2019 году основными направлениями для венесуэльской нефти были азиатские рынки, на которые приходилось около 65\% всего экспорта. Кризис, вызванный COVID-19, значительно повлиял на цены: в период с января по май 2020 года средняя стоимость венесуэльской нефтяной корзины сырой нефти была на 67\% ниже, чем за тот же период 2019 года. С другой стороны, были введены новые санкции в отношении компаний, которые занимаются торговлей и транспортировкой венесуэльской сырой нефти, что вызвало дополнительные трудности при экспорте нефти в страну и значительное увеличение объема товарноматериальных запасов. Это привело к применению политики предоставления больших скидок на корзину венесуэльской сырой нефти для стимулирования покупок.

Совместная деятельность по экспорту и импорту вызвала ухудшение товарного баланса почти на 10172 млн. долл., увеличившись с профицита в 20895 млн. долл. в 2018 году до 10723 млн. долл. в 2019 году. Если учитывать результаты счетов доходов, услуг и товаров, текущий счет внешнего сектора Венесуэлы имел дефицит, эквивалентный 0,7\% ВВП, что контрастирует с профицитом, наблюдавшимся в 2018 году, который был эквивалентен 4,9\% ВВП.

В результате всех этих элементов, согласно ЭКЛАК, ВВП сократился на 26\% в 2020 году, что 
является вторым годом, когда падение будет больше или равно 26\%, и подразумевает совокупное сокращение ВВП, которое составит 74\% с 2013 г. [9].

За последние 20 лет ни одна официальная инициатива не дала положительного эффекта в пользу диверсификации экспортной деятельности. Точно так же не было необходимых стимулов на институциональном, правительственном и налоговом уровнях, чтобы способствовать экспорту продукции, произведенной в Венесуэле.

В связи со всем вышеперечисленным актуальна необходимость предложения решений относительно диверсификации неэнергетического экспорта для получения страной валютного дохода. Например, комплексная программа макроэкономической перестройки с многосторонней поддержкой и / или финансированием, являющаяся одним из наиболее важных элементов для генерации иностранной валюты национальной экономики, экономической деятельности, занятости и богатства.

Однако для того, чтобы такая экспортная деятельность была успешной, она должна включать в себя следующие элементы: долгосрочный план стимулирования экспорта, макропроекты для экспортной инфраструктуры с комплексными долгосрочными планами, крупномасштабное государственно-многостороннее финансирование, дифференцированные ставки, особые условия, налоговые льготы, бизнес-тренинги и тренинги для экспортно-ориентированной предпринимательской деятельности. Всесторонняя поддержка исследовательских центров для исследования новых продуктов, промышленного дизайна, оценки экспортных проектов, в которых Венесуэла имеет сравнительные и конкурентные преимущества для их развития.

В то же время важно отметить, что международная торговля претерпевает серьезные изменения, такие как технологии и рост международной торговли услугами, основанными на знаниях, в рамках Четвертой промышленной революции, которая бросает вызов классическим сравнительным преимуществам, основанным на природных ресурсах, поскольку в новых коммерческих отношениях в глобальном мас- штабе приоритет отдается таким областям, как инновации, оцифровка и создание товаров с интенсивным использованием интеллектуальной собственности.

В таком порядке идей консолидация динамичной внешней торговли потребует понимания этих явлений, чтобы также сформулировать коммерческую политику, которая способствует развитию технологических преимуществ посредством продвижения и финансирования инновационных экосистем, цифровых платформ и ускорителей предпринимательства. В этом смысле необходимо содействовать коммерческой реинтеграции Венесуэлы в международную торговлю в контексте цифровых индустрий и технологических потрясений.

В контексте новой мировой экономики необходимо выстраивать новую торговую политику, адаптирующуюся к преобразованиям, которые претерпела современная международная торговля из-за структурных факторов, изменивших торговые модели, а также способы их обмена и коммерциализации товаров и услуг.

Нефтяная отрасль и энергетический потенциал венесуэльской экономики не будут потеряны. Нет никаких сомнений в том, что это будет ключевая отрасль в строительстве новой страны, но восстановление добычи нефти по самым консервативным прогнозам потребует инвестиций в миллиарды долларов.

Необходимо содействовать будущему коммерческому внедрению Венесуэлы, исходя из подхода, учитывающего новые глобальные производственные и коммерческие модели. Воспользоваться возможностями для развития экспортной и предпринимательской культуры, которая позволяет диверсифицировать производственную матрицу для восстановления ВВП и заложить основы для структурных изменений во внешней торговле Венесуэлы, повышения конкурентоспособности и использования коммерческих и финансовых возможностей. В противном случае технологический и производственный разрыв с остальным миром будет продолжать увеличиваться и заставит страну сместить новую динамику мировой торговли.

\section{Библиографический список}

1. Родригес П., Родригес Л. Нефть как инструмент прогресса. Каракас, Издания IESA, 2013 г., С. 244.

2. Каррера Д.Г. Современная история Венесуэлы. Методологические основы. Каракас, Центральный университет Венесуэлы. Выпуски библиотеки, 1977. С. 78. 
3. МЕРКОСУР. Приостановка Венесуэлы в МЕРКОСУР. [Электронный ресурс]. URL: https://www.mercosur.int/ suspension-de-venezuela-en-el-mercosur/.

4. Курсио П. Падение производства в Венесуэле. Причины. [Электронный ресурс]. URL: https:// observatoriodetrabajadores.wordpress.com/2019/10/31/caida-de-la-produccion-en-venezuela-causas pascualina-curcio-curcio/.

5. Курсио П. Падение производства в Венесуэле. Причины. [Электронный ресypc]. URL: https:// observatoriodetrabajadores.wordpress.com/2019/10/31/caida-de-la-produccion-en-venezuela-causas pascualina-curcio-curcio/.

6. PETRÓLEOS DE VENEZUELA, S.A. И ЕГО ДОЧЕРНИЕ ПРЕДПРИЯТИЯ (PDVSA) (Собственность БолИварианской Республики Венесуэла) Консолидированная финансовая отчетность 31 декабря 2016 г. С отчетом независимых аудиторов. [Электронный ресурс].URL: http:/www.pdvsa.com/images/pdf/estado_financiero/ PDVSAestado_financiero_espaol_16.pdf.

7. Экономические санкции как коллективное наказание: на примере Венесуэлы. [Электронный ресурс]. URL: http://cepr.net/images/stories/reports/venezuelasanctions-2019-05-spn.pdf.

8. Центральный банк Венесуэлы (BCV). [Электронный ресурс]. URL: http://www.bcv.org.ve/estadisticas/ comercio-exterior.

9. Экономическое исследование Латинской Америки и Карибского бассейна. [Электронный ресурс]. URL: 2020https://repositorio.cepal.org/bitstream/handle/11362/46070/91/EE2020_Venezuela_es.pdf.

10. Экономическая комиссия для Латинской Америки и Карибского бассейна (ЭКЛАК). Обзор экономического положения Латинской Америки и Карибского бассейна 2020: основные факторы, определяющие налогово-бюджетную и денежно-кредитную политику в эпоху после COVID-19. [Электронный pecypc]. URL: https://www.cepal.org/es/publicaciones/46070-estudio-economico-america-latina-caribe-2020-principalescondicionantes 